\title{
Selected Topics on Socio-technical Perspective in Information Systems: Editorial Introduction to Issue 18 of CSIMQ
}

\author{
Peter Bednar ${ }^{1}$ and Ilia Bider ${ }^{2 *}$ \\ ${ }^{1}$ School of Computing, University of Portsmouth, Buckingham Building, Lion Terrace, \\ Portsmouth PO1 3HE, UK \\ ${ }^{2}$ Department of Computer and System Sciences of Stockholm University, Stockholm, \\ Sweden \\ peter.bednar@port.ac.uk, ilia@dsv.su.se
}

This thematic issue of the Complex Systems Informatics and Modeling Quarterly journal is dedicated to using a socio-technical perspective in the Information Systems (IS) field. It contains a selection of extended papers presented at STPIS'18 - 4th International Workshop on SocioTechnical Perspective in IS Development [1], [2]. The workshop featured 11 presentations, five of which were extended for publication in this issue. The extended articles contain at least $30 \%$ new material compared to the initial papers. After the extension, all articles went through two rounds of reviews to ensure the quality of the papers published in this issue. STPIS papers cover both theoretical and practical aspects of using a socio-technical perspective in IS, which is reflected in the current issue that contains both theoretically and practically oriented papers.

The first article of this thematic issue is entitled "Applying Socio-technical Thinking in the Competitive, Agile, Lean, Data-Driven World of Knowledge Work and Smart, Service-Oriented, Customer-Centric Value Creation Ecosystems" and has been written by Steven Alter. This article contains critique of an archetype socio-technical approach and suggests a revisited and new contemporary socio-technical approach to deal with the highly dynamic business world of today.

The second article is entitled "Extending Business Process Models with Appreciation", and it has been written by Irina Rychkova, Gil Regev and Alain Wegmann. The article suggests a new way of modeling business processes based on the idea that each process is aimed at maintaining a homeostasis. The article also demonstrates the practical usefulness of the approach.

The next two articles are devoted to applying a socio-technical perspective to the security domain. The first one is entitled "Deriving Cyber Security Risks from Human and Organizational Factors - A Socio-technical Approach", and it has been written by Thomas Richard McEvoy and Stewart James Kowalski. The article uses a socio-technical approach to identifying security risks in an organization. The second security article is entitled "A Sociotechnical Systems Approach to Design and Support Systems Thinking in Cybersecurity and Risk Management Education", and it has been written by Erjon Zoto, Mazaher Kianpour, Stewart

\footnotetext{
Corresponding author

(C) 2019 Peter Bednar et al. This is an open access article licensed under the Creative Commons Attribution License (http://creativecommons.org/licenses/by/4.0).

Reference: P. Bednar and I. Bider, "Selected Topics on Socio-technical Perspective in Information Systems: Editorial Introduction to Issue 18 of CSIMQ," Complex Systems Informatics and Modeling Quarterly, CSIMQ, no. 18, pp. I-II, 2019. Available: https://doi.org/10.7250/csimq.2019-18.00
}

Additional information. Author ORCID iD: P. Bednar - https://orcid.org/0000-0002-3631-2626, I. Bider - https://orcid.org/00000002-3490-6092. PII S225599221900102X. Received: 26 April 2019. Available online: 30 April 2019. 
James Kowalski, and Edgar Alonso Lopez-Rojas. The article suggests a way how a sociotechnical approach can be introduced into the cybersecurity education.

The fifth article by Paola Mauri is entitled "Using Maps to Bridge the Socio-technical Gap: A Practitioner's Experience Report". This article represents an experience report written by a management consultant using a socio-technical perspective in her daily work.

We are grateful to all the people who have contributed to this thematic issue, including the authors and the reviewers of the articles invited to this thematic issue. We are also thankful to the managing editor of CSIMQ Marite Kirikova for her support throughout the whole process of preparation of this issue.

\section{References}

[1] Proceedings of the 4th International Workshop on Socio-Technical Perspective in IS development (STPIS'18). CEUR Workshop Proceedings. (Accessed May 2018) Available: http://ceur-ws.org/Vol-2107/

[2] STPIS: 4th International Workshop on Socio-Technical Perspective in IS development (STPIS'18). (Accessed 2018) Available: https://stpis2018.blogs.dsv.su.se/ 